\title{
Availability and Rational Use of Drugs in Primary Healthcare Facilities Following the National Drug Policy of 1982: Is Bangladesh on Right Track?
}

\author{
Syed Masud Ahmed and Qazi Shafayetul Islam \\ Research and Evaluation Division, BRAC, BRAC Centre, 75 Mohakhali, Dhaka 1212, Bangladesh
}

\begin{abstract}
In Bangladesh, the National Drug Policy (NDP) 1982 was instrumental in improving the supply of essential drugs of quality at an affordable price, especially in the early years. However, over time, evidence showed that the situation deteriorated in terms of both availability of essential drugs and their rational use. The study examined the current status of the outcome of the NDP objectives in terms of the availability and rational use of drugs in the primary healthcare (PHC) facilities in Bangladesh, including affordability by consumers. The study covered a random sample $(\mathrm{n}=30)$ of rural Upazila Health Complexes (UHCs) and a convenient sample ( $\mathrm{n}=20)$ of urban clinics (UCs) in the Dhaka metropolitan area. Observations on prescribing and dispensing practices were made, and exit-interviews with patients and their attendants, and a mini-market survey were conducted to collect data on the core drug-use indicators of the World Health Organization from the health facilities. The findings revealed that the availability of essential drugs for common illnesses was poor, varying from $6 \%$ in the UHCs to $15 \%$ in the UCs. The number of drugs dispensed out of the total number of drugs prescribed was higher in the UHCs (76\%) than in the UCs (44\%). The dispensed drugs were not labelled properly, although $>70 \%$ of patients/care-givers $(n=1,496)$ reported to have understood the dosage schedule. The copy of the list of essential drugs was available in $55 \%$ and $47 \%$ of the UCs and UHCs respectively, with around two-thirds of the drugs being prescribed from the list. Polypharmacy was higher in the UCs (46\%) than in the UHCs (33\%). An antibiotic was prescribed in $44 \%$ of encounters $(n=1,496)$, more frequently for fever $(36-40 \%)$ and common cold $(26-34 \%)$ than for lower respiratory tract infection, including pneumonia (10-20\%). The prices of key essential drugs differed widely by brands (500\% or more), seriously compromising the affordability of the poor people. Thus, the availability and rational use of drugs and the affordability of the poor people have remained to be achieved in Bangladesh even 27 years after approving the much-acclaimed NDP 1982.
\end{abstract}

Key words: Costs and cost analysis; Drug-use; Drugs; Health expenditure; National drug policy; Bangladesh

\section{INTRODUCTION}

The availability of essential drugs (medicines considered indispensable for the treatment of a disease) and the affordability of the common people are crucial for the successful functioning of any health system (1). It is also an important factor to prevent

Correspondence and reprint requests should be addressed to:

Dr. Syed Masud Ahmed

Senior Research Coordinator

Research and Evaluation Division

BRAC

BRAC Centre

75 Mohakhali, Dhaka 1212

Bangladesh

Email: ahmed.sm@brac.net

Fax: 880-2-8823542 bypassing of primary healthcare (PHC) facilities by the common people (2). In Bangladesh, the National Drug Policy (NDP) 1982 was instrumental in improving the supply of essential drugs of quality at an affordable price, especially in the early years (3). An essential drugs list (EDL), approved by the Government, initially identified 150 drugs with controlled prices. Due to the policy of buying raw materials from international competitive markets under the new policy, the prices of essential drugs fell sharply in the subsequent years. During 19811991, the retail prices of drugs increased by $20 \%$ in the local market. The pharmaceutical industry in Bangladesh also developed rapidly following the implementation of the NDP 1982 (4). In 1980, eight multinational companies manufactured $75 \%$ of all products (by value) while indigenous phar- 
maceuticals now claim a market share of more than $75 \%(5)$.

Evidence showed that essential drugs were not often available, especially in the government health facilities (6). Besides, the irrational use of drugs, such as over-prescribing, prescribing of multiple drugs, use of unnecessary expensive drugs, and overuse of antibiotics and injections were observed $(3,7)$. The number of regulated drugs was reduced to 117 in 1993 and again increased to 209 in 2007 to reflect advancement in medical sciences (8), with loosening of control in fixing the prices of non-essential drugs in particular and all drugs in general (9).

The Central Medical Store of the Government distributes drugs in the public hospitals and facilities (10). The retail distribution presents a totally chaotic situation without any regulatory mechanism. Although the persons dispensing drugs at the retail shops should have at least a short training of eight weeks before applying for a license, in practice, this is hardly followed. Of 200,000 drug stores that sell drugs over-the-counter in the country, only 76,000 (38\%) are approved (licensed) by the Government (11).

The retail drug shops are often the first and the only source of healthcare outside home for the majority of patients in developing countries (12), and Bangladesh is no exception to this. Anybody can buy any drug in any quantity, including addicting drugs, from these shops without any prescription. Bangladesh is one of the few countries where there is high out-of-pocket (OOP) expenditure on drugs by households, which amounts to around 70\% of the total OOP expenditure on health (13). Aggressive marketing by the pharmaceutical companies in Bangladesh and the free availability of 'prescription only' drugs in the unlicensed and unregulated retail outlets (drug shops) have worsened the situation for the rational use of drugs $(14,15)$.

The meagre resources of the Directorate of Drug Administration (the supreme regulatory authority in the country for drug-related affairs) have made it practically impossible to monitor and regulate these drug stores, including the large pharmaceutical sector in the country (5). As a result, many drugs enter the market without proper quality-assessment procedures, and the market is flooded with counterfeit, substandard and expired drugs (16). For example, in a testing by the drug regulating authority, $69 \%$ of paracetamol tablets and $80 \%$ of ampicillin capsules, manufactured by small companies, were found to be below the acceptable standard, and results of an assay of drugs involving 15 brands of ciprofloxacin showed that $47 \%$ of collected samples contained less-than-required ingredients (17).
In the public sector, primary-level healthcare in Bangladesh consists of Upazila Health Complexes (UHCs), with inpatient (31-bed) and basic laboratory facilities, and a network of sub-centres and community health workers. Besides the shortage of skilled health workforce, these centres also lack appropriate diagnostic facilities and medicines, causing a gradual decline in the use of government health services for the treatment of diseases from $17 \%$ in 2000 to $13 \%$ in 2003 (18). It was observed that diagnoses made at the PHC level were mainly based on presenting complaints, history-taking, and clinical examinations (19).

There has been no comprehensive study of the NDP in Bangladesh, which requires investigation of the state of the indicators relating to structure (pharmaceutical system's capacity to achieve the stated goals), process (the degree to which necessary activities are carried out and progress over time) and outcome (to assess availability, affordability, quality, and rational use) (20). A baseline survey, conducted in 1992 on the use of drugs at some public-sector PHC facilities in rural Bangladesh, found that the availability and use of essential drugs were very low and irrational, and over-prescribing of drugs was common (7). Since then, no study has been conducted to track the changes over the years and guide practitioners. This study aimed at fulfilling this knowledge gap by investigating the availability and rational use of drugs and the affordability of the common people in both rural and urban PHC facilities in the country. This is expected to help the policy-makers/practitioners understand the present situation and take remedial measures to reach the poor with 'quality drugs at low cost' (21). Besides, responsiveness of the PHC facilities and client satisfaction were also explored.

\section{MATERIALS AND METHODS}

Data for the study originated from a nationwide survey in 2009 on the rational use of essential drugs in the PHC facilities (22). The study was designed as a facility-based cross-sectional survey to collect data on core drug-use indicators as recommended by the World Health Organization (WHO) which could be implemented "by individuals without special training or access to many resources" (23).

\section{Sampling}

Due to the time and resource constraints, the sample was limited to 30 rural UHCs and 20 UCs in the Dhaka City Corporation (DCC) area. The 30 UHCs were randomly selected from the six divisions proportionate to size, i.e. the division with the largest number of UHCs provided the largest proportion of 30 UHCs in the sample. Again, two 
UCs in the DCC area were selected at random from each of the 10 zones where the Urban PHC Project II provides outpatient services under a partnership agreement with non-government organizations (NGOs) selected through competitive bidding (24). The list of the UCs was provided by the NGOs in their respective working areas.

Thirty patients attending the outpatient departments of each of the UHCs and UCs for common acute illnesses were enrolled in the study. They were selected from the total number of patients visiting the PHC facility in working days (consecutive) until the required number of patients was obtained. Patients were selected by systematic random sampling to avoid bias from timing of the survey (rush hours in the beginning or end of clinic sessions) or freshness or fatigue of the healthcare providers/ workers. Thus, 1,500 patients-900 in the UHCs and 600 in the UCs-were included in the study.

\section{Techniques and tools}

Data were collected through observations on prescribing and dispensing practices and recording information, exit-interviews with patients and their attendants (for understanding dosage, responsiveness of the system, and satisfaction with services), and a mini-market survey (to elicit prices of essential drugs for common illnesses). A pretested structured form was used for recording relevant data from patient-provider interactions. Another pretested, semi-structured questionnaire was used for recording information from exit-interviews of patients or attendants. Finally, a checklist was used for recording price-related information. The datacollection instruments were prepared based on literature review and peer experience. These were then pretested by a core group of interviewers who received intensive training and orientation from the researchers conducted in an area outside the study areas.

Based on the Government-approved EDL, a reference list of key essential drugs for common illnesses (henceforth reference list), selected from reality check of patient registers at the UHCs, was prepared (8). This reference list of 20 drugs was used for checking the availability of drugs in the PHC facilities and also for collecting information on prices through the mini-market survey.

\section{The survey}

Trained interviewers collected data during February-March 2009. To understand the prescribing and dispensing practices, the selected UHC/UC was observed for two consecutive days during usual office hours (9 am-1:30 pm). The two-member survey team started the day by taking permission from the chief executive of the UHC/UC to proceed with the study, exploring whether there was an EDL (posted in public or in file) in the facility and going through the records of the past seven days to get an idea about the daily average patient-load of the facility. The latter information was used for deciding upon the interval required for taking the systematic random sample of 30 patients.

One interviewer placed himself at the door of the Doctor's Chamber and recorded the time of entry and exit of the sampled patient using a stopwatch. The prescribing indicators were recorded from the prescription slip immediately after the doctorpatient interaction was over. Another interviewer, posted near the dispensary, followed the sampled patient when s/he came out of the doctor's chamber. The time of submitting the prescription slip to the dispenser and the time when drugs were dispensed were recorded, and the dispensing time was calculated. The number of drugs in the prescription slip, the number of drugs served by the dispenser, and labelling of the drugs served were recorded. Also, for confirming the availability of drugs, the reference list of drugs was read in front of the storekeeper/dispenser, and he was asked to show the drugs, if available. When the drug was shown, only then it was recorded as available.

The same interviewer conducted an exit-interview with the patient or his/her attendant to elicit information on their understanding of dosage, responsiveness of the system, and satisfaction with services. The interview was conducted in a place away from the prescribing and dispensing site but within the premises of the facility. The whole process continued in this cycle until the desired number of patients was enrolled.

Finally, a mini-market survey was conducted in the rural areas to find the extent of variation in market prices of essential drugs for common illnesses. Near each UHC in the sample, 10 drug stores were randomly chosen, and the minimum and maximum prices of drugs included in the reference list were recorded. The prices were obtained from the sales people at the drug stores. The cost of a full-course of drugs for three common illnesses among the study subjects was reviewed to understand the affordability of the extreme poor people.

Management and analysis of data

The SPSS PC+ software (version 12) was used for analyzing data. The summary statistics of the different drug-use indicators were compiled to compare the rural and urban facilities (UHCs and UCs in the DCC area respectively). 


\section{Ethical clearance}

The study proposal passed through the usual institutional review process at the Research and Evaluation Division of BRAC and the ethical review board of the James P. Grant School of Public Health, BRAC University. No invasive procedure was done. Informed verbal consents were obtained from the respondents who were largely illiterate or semi-literate. The written consent form was read out and explained to the respondents. When the investigator was satisfied that the respondent understood it, including its implications, and had agreed to participate, only then s/he was included in the survey. Anonymity of the respondents was maintained at all stages of analysis of data.

\section{RESULTS}

In total, 900 patient-provider encounters in the UHCs and 600 patient-provider encounters in the UCs (5 patients declined to be interviewed) were observed. Around $27 \%$ and $40 \%$ of the patients attending the UHCs and UCs respectively were aged $\leq 5$ years while the proportion of patients aged $\geq 60$ years attending the UHCs was twice (7.2\%) that of the UCs (3.4\%). In both the types of facilities, more women sought care than men.

\section{Availability of drugs}

Forty-seven percent of the UHCs and 55\% of the UCs had a copy of the EDL (Table 1). None of the facilities had all the 20 drugs included in the reference list of key essential drugs for common illnesses. However, $6 \%$ of the UHCs and $15 \%$ of the UCs had at least 15 of the 20 drugs in the reference list.

\section{Rational use of drugs}

The average number of drugs prescribed per visit (prescription) was 2.2 in the UHCs and 2.5 in the UCs (Table 1). The proportion of encounters $(n=1,496)$ with an antibiotic prescribed was around
$44 \%$. In more than $60 \%$ of the encounters, drugs were prescribed from the EDL. Polypharmacy or prescribing three or more drugs was quite common, especially in the UCs $(46 \%$ opposed to $33 \%$ in the UHCs) (Table 2).

Table 3 shows the extent of prescribing antibiotics for selected common illnesses (exclusive) by the two types of facilities. A greater tendency was observed to prescribe antibiotics for fever (40\% in the UHCs and 36\% in the UCs) and common cold/cough (26\% in the UHCs and $34 \%$ in the UCs) than for acute respiratory infection (ARI) (including pneumonia) (10\% in the UHCs and 19\% in the UCs). Thus, the UCs performed relatively rational when prescribing antibiotics. In all the cases, antibiotics were prescribed without any laboratory investigation.

\section{Variation in prices of drugs}

A wide variation was observed in the lowest and the highest market prices of the same drug. The differences were sometimes more than 500\%, e.g. tablet iron-folic acid-1,650\%, tablet mebendazole-900\%, and benzyl benzoate lotion-817\% (Table 4).

Table 5 shows the cost of drugs for a standard regimen for the treatment of three common illnesses, such as hyperacidity (including peptic ulcer), amoebic dysentery, and acute respiratory tract infection (including pneumonia). The cost varied from $7 \%$ to $8 \%$ of weekly income of the extreme poor for treating hyperacidity and amoebic dysentery to $20 \%$ for treating ARI with antibiotics.

\section{Responsiveness of the system and client satisfaction}

The average consulting and dispensing time was less in the UHCs (1-2 minutes) than in the UCs (2-6 minutes) (Table 6). The proportion of drugs dispensed out of those prescribed was much higher

\begin{tabular}{|lcc|}
\hline Table 1. Availability and use of drugs by study areas (\%) & & \\
\hline Characteristics & $\begin{array}{c}\text { Rural UHCs } \\
(\mathrm{n}=900)\end{array}$ & $\begin{array}{c}\text { UCs in DCC area } \\
(\mathrm{n}=596)^{*}\end{array}$ \\
\hline $\begin{array}{l}\text { Availability } \\
\quad \text { Facilities having a copy of the list of essential drugs }\end{array}$ & 47.0 & 55.0 \\
$\quad \begin{array}{l}\text { Facilities where at least 15 key essential drugs from the list } \\
\text { of essential drugs are available }\end{array}$ & 6.0 & 15.0 \\
Use & 2.2 & 2.5 \\
$\quad \begin{array}{l}\text { Average number of drugs per encounter } \\
\text { Of encounters with an antibiotic prescribed }\end{array}$ & 45.0 & 42.7 \\
Of drugs prescribed from the list of essential drugs & 63.0 & 66.1 \\
\hline $\begin{array}{l}\text { *Four patients had incomplete data and excluded from analysis; DCC=Dhaka City Corporation; } \\
\text { UCs=Urban clinics; UHCs=Upazila Health Complexes }\end{array}$ & \\
\hline
\end{tabular}




\begin{tabular}{|lcc|}
\hline \multicolumn{3}{|l|}{ Table 2. Polypharmacy by study areas (\%) } \\
\hline $\begin{array}{l}\text { Prescription } \\
\text { containing } \\
\text { the number } \\
\text { of drugs }\end{array}$ & $\begin{array}{c}\text { Rural } \\
\text { UHCs } \\
(\mathrm{n}=900)\end{array}$ & $\begin{array}{c}\text { UCs in DCC } \\
\text { area }(\mathrm{n}=596)^{*}\end{array}$ \\
\hline 1 & 18.1 & 14.8 \\
2 & 49.0 & 38.9 \\
3 & 27.0 & 30.0 \\
4 or more & 5.9 & 16.2 \\
\hline *Four patients had incomplete data and excluded \\
from analysis; DCC=Dhaka City Corporation; \\
UCs=Urban clinics; UHCs=Upazila Health \\
\hline
\end{tabular}

in the UHCs (76\%) than in the UCs (44\%). Only $65 \%$ of the drugs dispensed in the UHCs and $43 \%$ in the UCs were labelled (we considered drugs as labelled if these could be identified by either the inscription on its body or the name printed in the original package disbursed). While instructions on how to take drugs were given verbally, more than $70 \%$ of the patients or care-givers reported that they understood how to take the dispensed drugs.

\begin{tabular}{|lcc|}
\hline \multicolumn{3}{|c|}{\begin{tabular}{r} 
Table \\
\multicolumn{3}{|c|}{ Antibiotics prescribed for selected } \\
common illnesses by study areas (\%)
\end{tabular}} \\
\hline $\begin{array}{l}\text { Illnesses } \\
\text { for which } \\
\text { antibiotics were } \\
\text { prescribed }\end{array}$ & $\begin{array}{c}\text { Rural } \\
\text { UHCs } \\
(\mathrm{n}=405)\end{array}$ & $\begin{array}{c}\text { UCs in } \\
\text { DCC area } \\
(\mathrm{n}=255)\end{array}$ \\
\hline $\begin{array}{l}\text { Fever } \\
\text { Cough/ }\end{array}$ & 40.5 & 36.0 \\
common cold & 26.0 & 34.0 \\
$\begin{array}{l}\text { Lower } \\
\text { respiratory }\end{array}$ & & \\
tract infection & & \\
(including & & \\
pneumonia) & 10.0 & 19.0 \\
$\begin{array}{l}\text { Diarrhoea } \\
\text { Dysentery }\end{array}$ & 4.0 & 5.0 \\
$\begin{array}{l}\text { Body ache } \\
\text { Hyperacidity }\end{array}$ & 7.4 & 6.3 \\
Weakness & 2.1 & 7.0 \\
\hline $\begin{array}{l}\text { DCC=Dhaka City Corporation; UCs=Urban } \\
\text { clinics; UHCs=Upazila Health Complexes }\end{array}$ \\
\hline
\end{tabular}

Table 7 presents the findings of exit-interviews with the respondents, i.e. patients or their attendants. The mean waiting time at the UHCs (17 minutes) was reportedly less than that in the UCs (24 minutes). The UHCs performed poorly in terms of physical examinations (42\%) and maintenance of privacy (34\%) compared to the UCs (76\% and $66 \%$. respectively). A negligible proportion of the respondents from the UHCs reported paying unofficial charges. Overall, the level of satisfaction with services received from the UCs was quite high (95\% compared to $84 \%$ for the UHCs). This was further corroborated by the fact that most $(>90 \%)$ respondents mentioned they would suggest their friends/relatives to visit these facilities for seeking care.

\section{DISCUSSION}

The study was conducted to explore the current state of the availability and rational use of drugs and the affordability of the poor people in rural and urban Bangladesh. We used the core indicators of WHO to investigate drug-use in PHC facilities (25). The findings of the study revealed that the availability of key essential drugs for common illnesses was poor, and an unacceptable level of polypharmacy has been practised in the PHC facilities, including misuse and overuse of antibiotics. Generic prescribing was totally non-existent, and the affordability of the common people was severely compromised due to the variation in the retail prices of key essential drugs as much as $500 \%$ or more. The implications of these findings are discussed in the context of 'reaching the poor with quality drugs at low cost' as envisioned in the NDP 1982.

The EDL includes a core list of minimum drugs that satisfy the healthcare needs of the majority of the population in a particular country and should be available all times in adequate quantity and prescribed in appropriate dosage (20). While comparing with the previous survey of UHCs (7), an improvement was observed in relation to the availability of a copy of the EDL but deterioration was observed in the availability of key essential drugs for common illnesses. This is also consistent with the fact that lack of medicines was the most common complaint for which progressive deterioration in the use of government health services was observed during 1999-2003 (18).

Around two-thirds of the drugs were prescribed from the EDL. The drugs prescribed from the EDL in the UHCs recorded a substantial fall compared to what was found by Guyon et al. (from 85\% to 63\% in this study) (7). A similar level of prescription from the EDL was reported from Serbia (25) but a higher level was reported from India (26), Laos (27), and Tanzania (28). Thus, Bangladesh is lagging behind other low-income countries in this aspect. None of the drugs dispensed from any of the facilities was labelled properly (i.e. generic name of drug, dosage, etc.) as also observed in India (26), Tanzania (28), and Cambodia (29). However, the self-reported knowledge of patients or attendants on correct dosage observed in the UHCs (around 65\%) was comparable $(26,27)$ or even better than that reported in other studies $(28,29)$. 


\begin{tabular}{|c|c|c|c|c|}
\hline \multirow{2}{*}{\multicolumn{2}{|c|}{$\begin{array}{l}\text { Table 4. Lowest and highest prices of } s \\
\text { Reference drugs from the list prepared } \\
\text { by the study team (unit) }\end{array}$}} & \multicolumn{2}{|c|}{ Current market price $\left(\mathrm{Tk}^{\star}\right)$} & \multirow{3}{*}{$\begin{array}{c}\begin{array}{c}\% \text { of } \\
\text { difference }\end{array} \\
150\end{array}$} \\
\hline & & \multirow{2}{*}{$\begin{array}{c}\text { Lowest } \\
2.00\end{array}$} & \multirow{2}{*}{$\begin{array}{c}\text { Highest } \\
5.00\end{array}$} & \\
\hline 1 & ORS (1 pack) & & & \\
\hline 2 & Tablet co-trimoxazole (1 tablet) & 0.80 & 2.50 & 213 \\
\hline 3 & Syrup co-trimoxazole $(60 \mathrm{~mL})$ & 11.00 & 26.65 & 142 \\
\hline 4 & Syrup amoxicillin (100 mL) & 20.00 & 60.00 & 200 \\
\hline 5 & Tablet ciprocine (1 tablet) & 4.00 & 16.00 & 300 \\
\hline 6 & Syrup ciprocine (100 mL) & 37.00 & 95.00 & 157 \\
\hline 7 & $\begin{array}{l}\text { Tablet aluminium hydroxide + magnesium } \\
\text { hydroxide ( } 1 \text { tablet) }\end{array}$ & 0.50 & 1.50 & 200 \\
\hline 8 & $\begin{array}{l}\text { Tablet aluminum hydroxide + magnesium } \\
\text { hydroxide ( } 1 \text { tablet) }\end{array}$ & 11.00 & 65.00 & 491 \\
\hline 9 & Tablet ranitidine $150 \mathrm{mg}$ (1 tablet) & 1.00 & 4.00 & 300 \\
\hline 10 & Tablet paracetamol (500 mg) (1 tablet) & 0.50 & 2.00 & 300 \\
\hline 11 & Tablet aspirin (300 mg) (1 tablet) & 0.50 & 2.00 & 300 \\
\hline 12 & Tablet IFA (1 tablet) & 0.20 & 3.50 & 1650 \\
\hline 13 & Tablet B complex per bottle (45 tablets) & 12.00 & 90.00 & 650 \\
\hline 14 & Tablet ascorbic acid (1 tablet) & 0.50 & 2.00 & 300 \\
\hline 15 & Tablet mebendazole ( 1 tablet) & 0.50 & 5.00 & 900 \\
\hline 16 & Tablet albendazole ( 1 tablet) & 1.00 & 6.00 & 500 \\
\hline 17 & Tablet atenolol $50 \mathrm{mg}$ (1 tablet) & 0.70 & 4.00 & 330 \\
\hline 18 & Tablet prednisolone $5 \mathrm{mg}$ (1 tablet) & 0.50 & 1.50 & 200 \\
\hline 19 & Benzyl benzoate lotion 25\% (1 ph) & 6.00 & 55.00 & 817 \\
\hline 20 & Chloramphenicol eye drop $10 \mathrm{~mL}$ (1 bottle) & 10.00 & 35.00 & 250 \\
\hline 21 & Chloramphenicol eye ointment ( 1 tube) & 7.00 & 45.00 & 543 \\
\hline 22 & Xylometazoline nasal drop 15 mL (1 bottle) & 6.00 & 35.00 & 483 \\
\hline 23 & Miconazole ointment $10 \mathrm{~g}$ (1 tube) & 13.00 & 90.00 & 592 \\
\hline 24 & Tablet metronidazole $400 \mathrm{mg}$ (1 tablet) & 0.50 & 3.00 & 500 \\
\hline
\end{tabular}

Polypharmacy or prescribing three or more drugs increases the risk of drug interactions, dispensing errors, and proper comprehension of the correct dosage (25). In this study, we found polypharmacy on the rise: compared to 5\% polypharmacy reported earlier in UHCs (7), we found this to be 33\%, which should raise our concern. The proportion of polypharmacy was even higher (46\%) in our UCs compared to that found in Indonesia (30). The average number of drugs prescribed per encounter in the UHCs (2.2) was higher than that observed in the earlier study (1.4). Such a higher number was also observed in studies in Serbia (25), India (26), Laos (27), and Tanzania (28).

The proportion of encounters/prescriptions with an antibiotic prescribed was around 44\% when UHCs and UCs taken together; it was higher in the UHCs (45\%) compared to an earlier study in Bangladesh (25\%) (7) and other studies $(27,30)$. Of more concern is the fact that antibiotics were much less frequently used for lower respiratory tract infections and pneumonia where it is warranted. Such an irrational use of antibiotics is responsible for the development of antibiotic resistance (31).

The anarchy prevailing in the drug market is wellamplified by the wide variation in the prices of drugs by brands; sometimes the difference ranged from 500\% to more than 1,000\%. A similar situation was also observed in other low- and middleincome countries (32). This seriously compromises the affordability of the poor people for quality drugs. Lower-priced drugs are mainly marketed by small local companies against whom complaints of producing low-quality drugs are common (33). As observed in the present study, the cost of a stand- 


\begin{tabular}{|c|c|c|c|c|}
\hline Illness/disease & Drug & $\begin{array}{l}\text { Standard minimum } \\
\text { dose commonly } \\
\text { prescribed by } \\
\text { upazila doctors }\end{array}$ & $\begin{array}{c}\text { Cost (Tk) } \\
(\mathrm{US} \$ 1=\mathrm{Tk} 69)^{*}\end{array}$ & $\begin{array}{l}\text { Cost as } \\
\text { percentage } \\
\text { of weekly } \\
\text { income }\end{array}$ \\
\hline \multirow[t]{2}{*}{$\begin{array}{l}\text { Hyperacidity, } \\
\text { including peptic } \\
\text { ulcer }\end{array}$} & $\begin{array}{l}\text { Aluminium } \\
\text { hydroxide+ } \\
\text { magnesium } \\
\text { hydroxide } \\
\text { suspension }\end{array}$ & $\begin{array}{l}15-30 \mathrm{~mL} \text { everyday } \\
\text { up to } 6 \text { weeks or } \\
\text { until pain subsides }\end{array}$ & 55 (per week) & 13.28 \\
\hline & $\begin{array}{l}\text { Tab ranitidine } \\
150 \mathrm{mg}\end{array}$ & $\begin{array}{c}2 \text { tablets daily for } 4 \\
\text { weeks }\end{array}$ & 28 (per week) & 6.76 \\
\hline \multirow[t]{2}{*}{ Amoebic dysentery } & $\begin{array}{l}\text { Tablet } \\
\text { metronidazole } \\
400 \mathrm{mg}\end{array}$ & $\begin{array}{l}800 \mathrm{mg} 3 \text { times } \\
\text { daily for } 5 \text { days } \\
\text { (adult) }\end{array}$ & 30 & 7.24 \\
\hline & $\begin{array}{c}\text { Syrup } \\
\text { metronidazole }\end{array}$ & $\begin{array}{l}15 \text { mL daily for } 5 \\
\text { days (child) }\end{array}$ & 45 & 10.86 \\
\hline \multirow{3}{*}{$\begin{array}{l}\text { Lower respiratory tract } \\
\text { infection, including } \\
\text { pneumonia }\end{array}$} & $\begin{array}{c}\text { Capsule } \\
\text { amoxicillin }\end{array}$ & $\begin{array}{l}500 \mathrm{mg} 3 \text { times } \\
\text { daily for } 7 \text { days }\end{array}$ & 105 & 25.36 \\
\hline & $\begin{array}{c}\text { Syrup } \\
\text { amoxicillin }\end{array}$ & $\begin{array}{c}10 \mathrm{~mL} 3 \text { times daily } \\
\text { for } 7 \text { days (children } \\
\text { aged }>2 \text { years) }\end{array}$ & 90 & 21.73 \\
\hline & $\begin{array}{l}\text { Syrup co- } \\
\text { trimoxazole }\end{array}$ & $\begin{array}{c}10 \text { mL daily for } 7 \\
\text { days (children aged } \\
\text { up to } 5 \text { years) }\end{array}$ & 40 & 9.66 \\
\hline
\end{tabular}

ard regimen of treatment for a common illness was quite substantial for the extreme poor when compared with their income of one dollar a day. The poor regulatory and supervisory mechanism in the country contributes to this price-hike $(9,21)$. This high cost of medicines and the low availability of essential medicines due to the failure of the government regulatory mechanism were also observed in middle-income countries, such as Malaysia, with the relatively-stable and effective public-health system (34). Evidence shows that it is possible to improve the availability of essential drugs, including the affordability of consumers by market regulation throughout the supply-chain from the manufacturer to the patient and through the competitive purchasing process of raw materials $(35,36)$. As OOP expenditure for drugs is high in Bangladesh and all prescribed drugs are not always available at facilities, the poor regulation contributes to the catastrophic health expenditure for poor households $(18,37)$.

Responsiveness or responding to people's expectations is one of the main objectives of the health system (38). In the core indicators of WHO for the rational use of drugs, the quality of care provided

\begin{tabular}{|lcc|}
\hline Table 6. Patient-care indicators by study areas & \\
\hline Indicator & $\begin{array}{c}\text { Rural } \\
\text { UHCs (n=900) }\end{array}$ & $\begin{array}{c}\text { UCs in DCC area } \\
(\mathrm{n}=596)^{*}\end{array}$ \\
\hline Average consultation time (minutes) & 1.8 & 5.8 \\
Average dispensing time (minutes) & 0.9 & 2.1 \\
\% of drugs actually dispensed & 76.3 & 44.0 \\
\% of drugs adequately labelled & 65.4 & 43.0 \\
\% of patient's knowledge of correct dosage & 73.0 & 76.0 \\
(self-reported) & & \\
\hline *Four patients had incomplete data and excluded from analysis; DCC=Dhaka City Corporation; \\
UCs=Urban clinics; UHCs=Upazila Health Complexes
\end{tabular}




\begin{tabular}{|c|c|c|c|c|c|c|}
\hline \multirow{2}{*}{$\begin{array}{l}\text { Characteristics of services } \\
\text { received }\end{array}$} & \multicolumn{3}{|c|}{ Rural UHCs } & \multicolumn{3}{|c|}{ UCs in DCC area } \\
\hline & $\begin{array}{c}\text { Male } \\
(\mathrm{n}=379)\end{array}$ & $\begin{array}{l}\text { Female } \\
(\mathrm{n}=521)\end{array}$ & $\begin{array}{c}\text { All } \\
(\mathrm{n}=900)\end{array}$ & $\begin{array}{c}\text { Male } \\
(\mathrm{n}=189)\end{array}$ & $\begin{array}{l}\text { Female } \\
(\mathrm{n}=406)\end{array}$ & $\begin{array}{c}\text { All } \\
(\mathrm{n}=595)^{*}\end{array}$ \\
\hline Waiting time at facilities (mean) & 14.6 & 18.6 & 16.9 & 23.9 & 24.6 & 24.5 \\
\hline $\begin{array}{l}\text { Doctors listened to problems } \\
\text { attentively }\end{array}$ & 94.0 & 94.0 & 94.0 & 98.0 & 99.0 & 99.0 \\
\hline $\begin{array}{l}\text { Physical examinations done } \\
\text { by doctors }\end{array}$ & 44.0 & 40.0 & 42.0 & 76.0 & 76.0 & 76.0 \\
\hline $\begin{array}{l}\text { Privacy was maintained by } \\
\text { doctors }\end{array}$ & 35.0 & 33.0 & 34.0 & 62.0 & 68.0 & 66.0 \\
\hline $\begin{array}{l}\text { All prescribed medicines were } \\
\text { given from the facility }\end{array}$ & 65.0 & 73.0 & 70.0 & 29.0 & 37.0 & 34.0 \\
\hline Paid unofficial charge(s) & 4.0 & 3.0 & 3.0 & 0.0 & 0.0 & 0.0 \\
\hline Satisfied with services & 84.0 & 83.0 & 84.0 & 95.0 & 95.0 & 95.0 \\
\hline $\begin{array}{l}\text { Will suggest to relatives/friends to } \\
\text { visit this facility }\end{array}$ & 93.0 & 93.0 & 93.0 & 99.5 & 98.0 & 99.0 \\
\hline
\end{tabular}

is measured by the time taken in consultation and dispensing (including time for instruction on how to take drugs). The average consulting and dispensing time in the UHCs increased from what was found earlier (15) but lagged behind other countries, e.g. Serbia (25). Such a short time is neither adequate for history-taking and examination of patients nor giving them sufficient information on the dosage of drugs and necessity for compliance. Also, lack of proper physical examinations of patients and maintenance of privacy question the responsiveness of the system.

This study is an improvement from the earlier study on the use of drugs at the UHCs (7). It covered a larger, representative sample of upazilas in the country and additionally included an urban sample from the DCC area. The sample-size was adequate as per recommendations of the International Network for the Rational Use of Drugs and WHO to compare facilities (23). On the other hand, due to practical reasons, we had to use proxy indicators for certain components, such as 'labelling', and we did not explore whether drugs prescribed followed the standard guidelines as most recorded diagnoses were non-specific.

\section{Conclusions}

Except the early years in the eighties, the NDP 1982 could not ensure the availability and rational use of drugs and the affordability of the common people over the long term in Bangladesh as exemplified in the present study. The situation has rather deteriorated in the past 15 years, especially in rural areas. Concerted efforts are needed to motivate and train those in the medical profession and allied health professions (e.g. nurses, paramedics, informal allopathic practitioners, drug dispensers, and manufacturers) about the benefits of generic prescribing (which can lead to cost savings) and prescribing from the national EDL, especially for the poor. Polypharmacy and overuse/misuse of drugs, especially antibiotics, should be discouraged to avoid drug resistance and its consequences. Besides, strengthening the regulatory capacity of the Directorate of Drug Administration for quality and price will be needed. Finally, the need of essential laboratory services at the PHC-level facilities for the proper diagnosis of illnesses which require antibiotics (e.g. childhood pneumonia) and the rational use of drugs cannot be overemphasized (39).

\section{ACKNOWLEDGEMENTS}

The study was funded by the Swedish International Development Agency through the Bangladesh Health Watch, a civil society initiative "to regularly and systematically measure and monitor the country's progress and performance in health."

The authors gratefully acknowledge the time and experiences shared by the staff of the participating UHCs and UCs in the study. Thanks are due to Dr. Abbas Bhuiya of icddr,b and Dr. Mushtaque R. Choudhury of the Rockefeller Foundation for their encouragement and guidance in conducting the study, and Prof. Md. Sayedur Rahman of the Bangabandhu Sheikh Mujib Medical University for helping in designing the study. Special thanks are due to Mr. Farid Ahmed of the Research and Evaluation Division, BRAC, for helping with data and field management and Mr. Hasan Shareef Ahmed for editing the manuscript. 


\section{REFERENCES}

1. Chaudhury RR, Parameswar R, Gupta U, Sharma S, Tekur U, Bapna JS. Quality medicines for the poor: experiences of the Delhi programme on rational use of drugs. Health Policy Plan 2005;20:124-36.

2. Swedish International Development Agency. Improving access to essential pharmaceuticals. Stockholm: Department for Democracy and Social Development, Swedish International Development Agency, 2001. $12 \mathrm{p}$.

3. Islam N. Bangladesh national drug policy: an example for the Third World? Trop Doct 1999;29:78-80.

4. Reich MA. Bangladesh pharmaceutical policy and politics. Health Policy Plan 1994;9:130-43.

5. Begum R. Pharmaceutical industries: potentials and possibilities. NDC J 2007;6:73-89.

6. Omer K, Cockcroft A. Bangladesh hospital improvement initiative: follow-up community based user's survey: final report. London: CIET Europe, 2003. 51 p. (http://www.ciet.org/_documents/2006227135026. pdf, accessed on 1 July 2011).

7. Guyon AB, Barman A, Ahmed JU, Ahmed AU, Alam MS. A baseline survey on use of drugs at the primary health care level in Bangladesh. Bull World Health Organ 1994;72:265-71.

8. Bangladesh. Ministry of Health and Family Welfare. List of essential drugs. Bangladesh Gazette Notification No. janashasthya-1/oushod-13/2006/187 dated 22 May 2008. Dhaka: Public Health-1 Branch, Ministry of Health and Family Welfare, Government of Bangladesh, 2008. (http://www.searo.who.int/LinkFiles/Essential_Drugs_and_Medicines_BAN1.pdf, accessed on 4 July 2011).

9. Roy P. Essential drugs turn costlier: 20 top pharmaceutical companies to set minimum selling price. Daily Star 2005 Oct 13;5:1.

10. World Health Organization. Drug control and distribution in Bangladesh: a case study. Geneva: World Health Organization, 1985. 8 p. (WHO/CONRAD/ $\mathrm{WP} / 2.4 .1$ ).

11. World Bank. Public and private sector approaches to improving pharmaceutical quality in Bangladesh. Dhaka: Human Development Unit, South Asia Region, World Bank, 2008. 48 p. (Bangladesh development series no. 23).

12. Kamat VR, Nichter M. Pharmacies, self-medication and pharmaceutical marketing in Bombay, India. Soc Sci Med 1998;47:779-94.

13. Bangladesh. Ministry of Health and Family Welfare. Bangladesh national health accounts, 1999-2001. Dhaka: Health Economics Unit, Ministry of Health and Family Welfare, Government of Bangladesh, 2003. 189 p.
14. Islam MS, Farah SS. Misleading promotion of drugs in Bangladesh: evidence from drug promotional brochures distributed to general practitioners by the pharmaceutical companies. J Public Health (Oxf) 2007;29:212-3.

15. Babu MM. Factors contributing to the purchase of over the counter (OTC) drugs in Bangladesh: an empirical study. Internet J Third World Med 2008;6:20. (http://www.ispub.com/journal/the-internet-journal-of-third-world-medicine/volume-6-number-2/ factors-contributing-to-the-purchase-of-over-thecounter-otc-drugs-in-bangladesh-an-empirical-study. html, accessed on 3 July 2011).

16. Fake drugs flood Bangladesh. Pharma industry: South Asia. A Chronicle Pharmabiz Special. Thursday, 28 October 2004. (http://saffron.pharmabiz. com/article/detnews.asp? articleid=24467\&sectio nid=50, accessed on 4 July 2011).

17. United States Pharmacopeia. A review of drug quality in Asia with focus on anti-infectives. Rockville, MD: United States Pharmacopeia, 2004. 51 p. (http:// www.usp.org/pdf/EN/dqi/aneReview.pdf, accessed on 2 February 2011).

18. Cockcroft A, Andersson N, Milne D, Hossain MZ, Karim $\mathrm{E}$. What did the public think of the health services reform in Bangladesh? Three national community-based surveys 1999-2003. Health Res Policy Systems 2007;5:1. (http://www.health-policy-systems. com/content/5/1/1, accessed on 2 February 2011).

19. Essential laboratory services for NGO primary health care clinics in Bangladesh. Health Sci Bull 2007;5:4-9.

20. Brudon P, Rainhorn JD, Reich MR. Indicators for monitoring national drug policies: a practical manual. 2nd ed. Geneva: World Health Organization, 1999:17-29.

21. Islam MS. A review on the policy and practice of therapeutic drug uses in Bangladesh. Calicut Med J 2006;4:e2.

22. Ahmed SM, Islam QS. Rational use of essential drugs in the public and private sector PHC facilities in Bangladesh: current situation and future directions. Dhaka: James P. Grant School of Public Health, BRAC University, 2009. 37 p. (Bangladesh Health Watch 2008 background paper no. 1).

23. World Health Organization. How to investigate drug use in health facilities: selected drug use indicators. Geneva: World Health Organization, 1993. 92 p. (WHO/DAP/93.1) (EDM research series no. 007).

24. Bangladesh. Ministry of Local Government, Rural Development \& Co-operatives. Second Urban Primary Health Care Project: quarterly performance report, Jan.- Mar. 2009. Dhaka: Project Management Unit, Ministry of Local Government, Rural Development \& Co-operatives, Government of Bangladesh, 2009. $44 \mathrm{p}$. 
25. Jankovic SM, Vasic LM, Maksimovic MR, Cupurdija VB, Kostic IR, Kovacevic ZN. An analysis of drug use indicators in primary care health facilities operating in the city of Kragujevac. General practice on-line 1999. (http://priory.com/fam/Kosovo.htm, accessed on 4 July 2011).

26. Karande S, Sankhe P, Kulkarni M. Patterns of prescription and drug dispensing. Indian J Pediatr 2005;72:11721.

27. Keohavong B, Syhakhang L, Sengaloundeth S, Nishimura A, Ito K. Rational use of drugs: prescribing and dispensing practice at public health facilities in Lao PDR. Pharmacoepidemiol Drug Saf 2006;5:344-7.

28. Nsimba SE. Assessing prescribing and patient care indicators for children under five years old with malaria and other disease conditions in public primary health care facilities. Southeast Asian J Trop Med Public Health 2006;37:206-14.

29. Chareonkul C, Khun VL, Boonshuyar C. Rational drug use in Cambodia: study of three pilot health centers in Kampong Thom province. Southeast Asian J Trop Med Public Health 2002;33:418-24.

30. Arustiyono. Promoting rational use of drugs at the community health centers in Indonesia. Boston: Department of International Health, School of Public Health, Boston University, 1999. (MPH dissertation). (http://archives.who.int/prduc2004/Resource_Mats/ Asia_papers/PROMOTING\%20RATIONAL\%20 USE\%20OF\%20DRUGS\%20IN\%20INDONESIA. htm, accessed on 4 July 2011).

31. Larsson M. Antibiotic use and resistance: assessing and improving utilization and provision of antibiotics and other drugs in Vietnam. Stockholm: Karolinska University Press, 2003. 92 p. (PhD thesis). (http:// publications.ki.se/jspui/bitstream/10616/38492/1/ thesis.pdf, accessed on 4 July 2011).

32. Mendis S, Fukino K, Cameron A, Laing R, Filipe A, Jr., Khatib $\mathrm{O}$ et al. The availability and affordability of selected essential medicines for chronic diseases in six low- and middle-income countries. Bull World Health Organ 2007;85:279-88.

33. Chowdhury N, Kabir ER. Per pill price differences across therapeutic categories: a study of the essential drugs brands marketed by multinational and local pharmaceutical companies in Bangladesh. Afr J Market Manage 2009;1:220-6.

34. Babar ZUD, Ibrahim MI, Singh H, Bukahri NI, Creese A. Evaluating drugs prices, availability, affordability, and price components: implications for access to drugs in Malaysia. PLoS Med 2007;4:e82.

35. Maïga D, Williams-Jones B. Assessment of the impact of market regulation in Mali on the price of essential medicines provided through the private sector. Health Policy 2010;97:130-5.

36. World Health Organization. The world medicines situation. Geneva: World Health Organization, 2004: 61-74. (WHO/EDM/PAR/2004.5).

37. van Doorslaer E, O'Donnell O, Rannan-Eliya RP, Somanathan A, Adhikari SR, Garg CC et al. Catastrophic payments for health care in Asia. Health Econ 2007; 16:1159-84.

38. World Health Organization. The world health report 2000. Health systems: improving performance. Geneva: World Health Organization, 2000. 215 p.

39. World Health Organization. Health laboratory services in support of primary healthcare in South-East Asia. 2nd ed. Geneva: World Health Organization, 2007. 235 p. (WHO regional publications, SEARO series no. 24). 